\title{
SHORT REPORT \\ Predominance of Clostridium difficile ribotypes 012, 027 and 046 in a university hospital in Chile, 2012
}

\author{
Á. PLAZA-GARRIDO ${ }^{1}$, J. BARRA-CARRASCO ${ }^{1}$, J. H. MACIAS ${ }^{2}$, \\ R. CARMAN ${ }^{3}$, W. N. FAWLEY ${ }^{4}$ M. H. WILCOX ${ }^{4,5}$, C. HERNÁNDEZ-ROCHA ${ }^{6}$, \\ A. M. GUZMÁN-DURÁN ${ }^{7}, M$. AlvareZ-LOBOS ${ }^{*}$ And D. PAREdeS-SABJA ${ }^{1 *}$ \\ ${ }^{1}$ Gut Microbiota and Clostridia Research Group, Departamento de Ciencias Biológicas, Facultad de Ciencias \\ Biológicas, Universidad Andrés Bello, Santiago, Chile \\ ${ }^{2}$ Departamento de Ciencias Médicas, Universidad de Guanajuato, León, México \\ ${ }^{3}$ Techlab Inc., Blacksburg, Virginia, USA \\ ${ }^{4}$ Leeds Teaching Hospitals NHS Trust, Leeds, UK \\ ${ }^{5}$ Leeds Institute of Biomedical and Clinical Sciences, University of Leeds, Leeds, UK \\ ${ }^{6}$ Departamento de Gastroenterología, Facultad de Medicina, Pontificia Universidad Católica de Chile, Santiago, \\ Chile \\ ${ }^{7}$ Departamento de Laboratorio Clínico, Facultad de Medicina, Pontificia Universidad Católica de Chile, \\ Santiago, Chile
}

Received 10 April 2015; Final revision 13 September 2015; Accepted 18 September 2015; first published online 22 October 2015

\section{SUMMARY}

In a 1-year survey at a university hospital we found that $20 \cdot 6 \%(81 / 392)$ of patients with antibiotic associated diarrohea where positive for $C$. difficile. The most common PCR ribotypes were $012(14 \cdot 8 \%), 027(12 \cdot 3 \%), 046(12 \cdot 3 \%)$ and $014 / 020(9 \cdot 9)$. The incidence rate was $2 \cdot 6$ cases of $C$. difficile infection for every 1000 outpatients.

Key words: Chile, Clostridium difficile, epidemiology, nosocomial infections, ribotype.

Clostridium difficile is the leading cause of healthcare-associated diarrhoea in adults and the aetiological agent of antibiotic-associated colitis [1]. During the last decade, $C$. difficile infection (CDI) epidemiology has experimented significant changes (i.e. emergence of hypervirulent strains) that have led to increased severity and mortality rates, reaching as high as $15 \%$ in some outbreaks [2].

In Chile, two early studies in 2000 demonstrated that CDI occurred with similar frequencies as in developed countries of North America and the European

\footnotetext{
* Author for correspondence: Dr D. Paredes-Sabja, Gut Microbiota and Clostridia Research Group, Departamento de Ciencias Biológicas, Facultad de Ciencias Biológicas, Universidad Andrés Bello, República 217, Santiago, Chile.

(Email: daniel.paredes.sabja@gmail.com) [D.P-S.]

(Email: alvarezl@med.puc.cl) [M.A-L.]
}

Union [3, 4], yet the toxinotype and ribotype of the clinical isolates was not analysed. Recently, we have reported the presence of the epidemic ribotype 027 in Chile causing two severe clinical cases of CDI, one of which ended in colectomy [5]. Simultaneously, the largest outbreak of CDI in Chile occurred in 2011 at the Dr. Alejandro del Río emergency hospital in Santiago, infecting 186 patients over an 8-month period (June 2011 to April 2012) [6]. This outbreak was caused by hypervirulent ribotype 027 stains and presented a mortality rate that reached a disturbing $20 \%$ [6]. Here, we report the most common PCR ribotypes of $C$. difficile over an 11-month period (July 2011 to June 2012) from a university hospital in Santiago, Chile.

Specimens were obtained from the Hospital Clínico de la Pontificia Universidad Católica de Chile. This is 
a teaching tertiary-level healthcare centre with 450 beds, of which 60 correspond to critical care services. During an 11-month period (July 2011-June 2012), liquid or soft stool specimens from 392 hospitalized patients suspected of having CDI were analysed by multiplex real-time PCR GeneXpert (Cepheid, USA). Eighty-one patients were positive for $C$. difficile and all positive samples were also positive for toxigenic culture of $C$. difficile, causing cytophatic effects in monolayers of Vero cells, as described previously [7]. An average of $7 \cdot 4$ cases of CDI per month was observed, with the lowest and highest incidence observed in July 2011 with zero cases and October of 2011 with 16 cases, respectively. The incidence rate of CDI during this period was $2 \cdot 6 \mathrm{CDI}$ cases/ 1000 discharges, which is fivefold lower than national rate of CDI cases reported in USA [8] but sixfold higher than those results reported in a multicenter European study [9]. The mean age of the study population was $58 \cdot 2 \pm 2 \cdot 7$ years, and $66 \%$ of the patients received antibiotics (i.e. cephalosporins, $\beta$-lactams, carbapenems, quinolones, macrolides, clindamycin, metronidazole, vancomycin), and no mortality associated with CDI was reported.

PCR ribotyping was performed according to a previously described method [10] with minor modifications. In brief, DNA of three colonies from each stool sample was isolated [5] and subjected to standard ribotyping using $C$. difficile $16 \mathrm{~S}$ rRNA and $23 \mathrm{~S}$ rRNA primers [10]. PCR reaction was done by adding $1 \mu 1$ crude template DNA diluted $1: 10$ to a $25 \mu$ l PCR mixture containing $10 \mathrm{~mm}$ Tris- $\mathrm{HCl}(\mathrm{pH} 8 \cdot 3)$ and $50 \mathrm{~mm} \mathrm{KCl}($ GeneAmp $1 \times$ PCR Buffer II; Applied Biosystems, USA), $4.0 \mathrm{~mm} \mathrm{MgCl}_{2}, 0.4 \mathrm{~mm}$ dNTP, 1.5 U Taq DNA polymerase (Fermentas, USA). The cycling conditions were $3 \mathrm{~min}$ at $94{ }^{\circ} \mathrm{C}$, followed by 35 cycles of denaturation at $94{ }^{\circ} \mathrm{C}$ for $60 \mathrm{~s}$, annealing at $57^{\circ} \mathrm{C}$ for $60 \mathrm{~s}$, and elongation at $72^{\circ} \mathrm{C}$ for $1 \mathrm{~min}$. A final elongation step of $5 \mathrm{~min}$ at $72{ }^{\circ} \mathrm{C}$ was performed. PCR products were analysed on $5 \%$ non-denaturing polyacrylamide gels for $45 \mathrm{~min}$ at $150 \mathrm{~V}$ and stained with ethidium bromide. Images were analysed using Gel Compare II Software (Applied Maths, Belgium). Band patterns were compared with those of the C. difficile Ribotype library at TechLab (USA) and at Leeds Institute of Molecular Medicine, University of Leeds (UK). A total of 27 PCR ribotypes were identified, the most abundant being $012(14 \cdot 8 \%), 027$ $(12 \cdot 3 \%), 046(12 \cdot 3 \%), 014 / 020(9 \cdot 9 \%), 001(4 \cdot 9 \%)$, and $023(4.9 \%)$ (Fig. 1a, b). Three unidentified ribotypes infecting a total of four patients were sent to
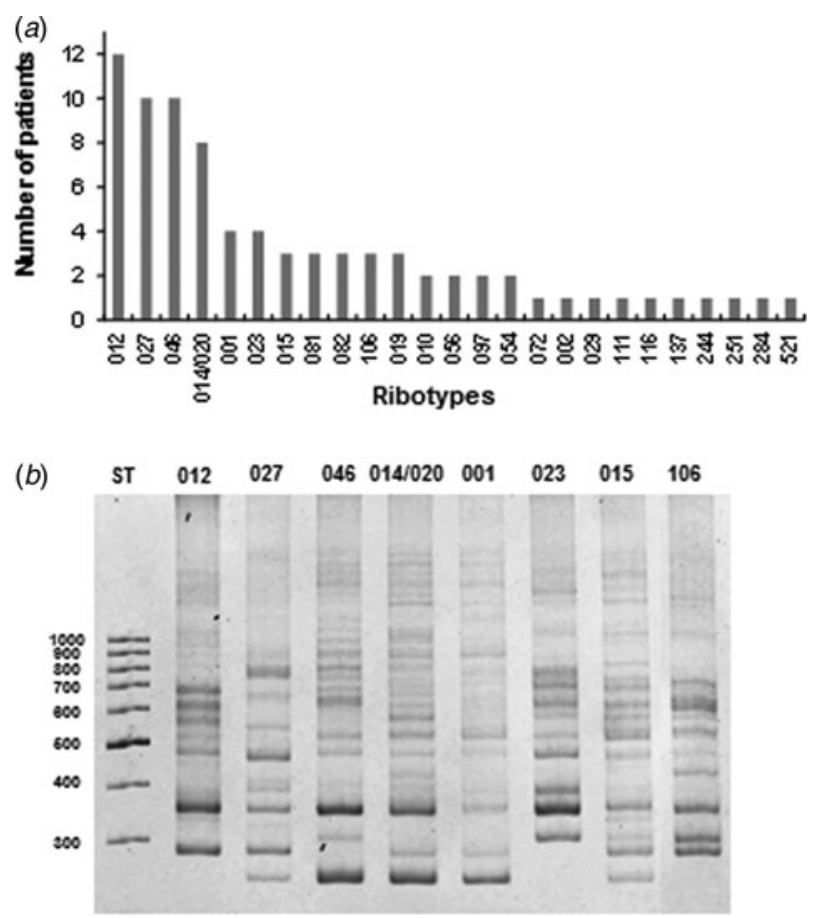

Fig. 1. (a) Frequency of $C$. difficile PCR ribotypes of 81 clinical isolates isolated between July 2011 and June of 2012 from a university hospital. (b) PCR ribotyping results show the band pattern of the ribosomal intergenic space regions of clinical isolates of the most frequent $C$. difficile clinical isolates. ST is 1000 -bp standard.

the Anaerobe Reference Laboratory for confirmation. Ribotypes 027, 082, 097 and 251 caused relapsing CDI in four patients ( $4.9 \%$ of CDI patients).

Presence of $t c d B$ and binary toxin was determined using GeneXpert PCR (Cepheid). C. difficile tcdA was detected by PCR amplification of a $3087 \mathrm{bp}$ fragment between $5090 \mathrm{bp}$ and $17 \mathrm{bp}$ downstream of the start and stop codon of $t c d A$, respectively, as described previously [11]. All 81 isolates were positive for $t c d B$, while $10 t c d A^{-} t c d B^{+}$variants were detected in ribotypes $012(1 / 12), 027(1 / 10), 046(1 / 10), 014 / 020$ (2/8), 001 (1/4), 023 (1/4), $106(1 / 3), 019$ (1/3) and 137 $(1 / 1)$. Twenty-two clinical isolates were positive for binary toxin, i.e. $012(1 / 12), 27$ (6/10), $046(2 / 10)$, 014/020 (2/8), $082(1 / 3), 019(2 / 3), 106(1 / 3), 081$ (1/3), $010(1 / 2), 054(2 / 2), 111(1 / 1), 116(1 / 1), 521$ (1/1). Interestingly, $t c d A^{-} t c d B^{+} c d t A B^{+}$variants occurred in ribotypes 012 (1/12), 014/020 (2/8), 027 (1/10), $046(1 / 10)$; the majority of these ribotypes are described as $t c d A^{+} t c d B^{+} c d t A^{-}$, while ribotype 027 is designated $t c d A^{+} t c d B^{+} c d t A B^{+}$.

Antimicrobial susceptibility testing to calculate the minimum inhibitory concentration of all clinical 
Table 1. Ribotypes with antibiotic resistance

\begin{tabular}{lrrrrrrr}
\hline \hline & & \multicolumn{7}{c}{ Antibiotic* } \\
\cline { 3 - 8 } Ribotype $\dagger$ & Total* & Mox & Van & Met & Rif & Ery & Clin \\
\hline 012 & $8 / 12$ & $8 / 12$ & $0 / 12$ & $0 / 12$ & $8 / 12$ & $4 / 12$ & $8 / 12$ \\
027 & $4 / 10$ & $4 / 10$ & $0 / 10$ & $0 / 10$ & $0 / 10$ & $4 / 10$ & $3 / 10$ \\
046 & $4 / 10$ & $4 / 10$ & $0 / 10$ & $0 / 10$ & $3 / 13$ & $1 / 10$ & $0 / 10$ \\
$014 / 020$ & $0 / 8$ & $0 / 8$ & $0 / 8$ & $0 / 8$ & $0 / 8$ & $0 / 8$ & $0 / 8$ \\
010 & $1 / 2$ & $0 / 2$ & $0 / 2$ & $0 / 2$ & $0 / 2$ & $1 / 2$ & $1 / 2$ \\
072 & $1 / 1$ & $0 / 1$ & $0 / 1$ & $0 / 1$ & $0 / 1$ & $1 / 1$ & $1 / 1$ \\
\hline \hline
\end{tabular}

* Resistance to antibiotics was considered at a minimum inhibitory concentration of: Mox (amoxicillin) $\geqslant 8 \mu \mathrm{g} / \mathrm{ml}$; Van (vancomycin) $\geqslant 32 \mu \mathrm{g} / \mathrm{ml}$; Met (metronidazole) $\geqslant 32 \mu \mathrm{g} / \mathrm{ml}$; Rif (rifaximin) $\geqslant 32 \mu \mathrm{g} / \mathrm{ml}$; Ery (erythromycin) $\geqslant 8 \mu \mathrm{g} / \mathrm{ml}$; Clin (clindamycin) $\geqslant 8 \mu \mathrm{g} / \mathrm{ml}$.

$\dagger$ Ribotypes the four most common ribotypes as well as those with presence of antibiotic-resistant isolates are shown. \$ Number of resistant and total isolates per ribotype are given.

isolates was performed with Etest strips (AB Biodisk, USA) as described previously [12]. Antibiotic resistance to amoxicillin (Mox), rifaximin (Rif), erythromycin (Ery) and clindamycin (Clin), but not to vancomycin and metronidazole was observed (Table 1). Only eight isolates of ribotype 012 were resistant to Mox, Rif and Clin, of which only four were resistant to Ery (Table 1). Only four isolates of ribotype 027 were resistant to Mox, Ery and Clin (Table 1). Three strains of ribotype 046 were resistant to Mox and Rif, while only one exhibited resistance to Mox and Ery (Table 1). Ribotype 072 strain showed resistance to Mox, Ery and Clin, while ribotype 010 isolates had resistance only to Ery and Clin (Table 1). No strains belonging to ribotype 014/020 exhibited resistance to the tested antibiotics (Table 1). None of the $t c d A^{-} t c d B^{+} c d t A B^{+}$variants that occurred in ribotypes $012(1 / 12), 014 / 020(2 / 8)$, $027(1 / 10), 046(1 / 10)$ exhibited antibiotic resistance.

We showed that the most common ribotypes between 2011 and 2012 at this particular hospital in Santiago, Chile, were 012 followed by 027, 046 and 014/020. This situation differs from that reported at the Dr. Alejandro del Río Hospital, where an outbreak that affected 186 patients was caused by hypervirulent ribotype 027 . The low incidence of CDI in the study hospital could be due to the implementation of the measures suggested by the Society for Healthcare Epidemiology of America (SHEA) [13]. The prevalence of ribotype 012 is as intriguing as in Costa Rica, where an outbreak associated with a $C$. difficile ribotype 012 variant, with increased virulence, was recently reported [14]. Ribotypes 012, 014/020 and 027 are also prevalent in European countries [9, 15, 16]. The prevalent ribotype 046 found in this study has also been shown to be prevalent in neonatal pigs [17] and in hospitals in Poland [18]. Chile, does not currently have a national surveillance policy for C. difficile; therefore, this report complements a recent report published by the Institute of Public Health of Chile concerning the rapid spread of NAP1/027/ST1 in Chilean public hospitals [19].

\section{ACKNOWLEDGEMENTS}

This work was supported by a grant from the Fondo Nacional de Ciencia y Tecnología de Chile FONDECYT Regular 1151025 to D.P-S.; Fondo Nacional de Innovación en Salud CONICYTFONIS SA12|2197, FONDECYT Regular 1131012 to M.A-L; FONDECYT Inicio 1130502 to C.H-R.

Angela Plaza-Garrido is a PhD student in the Molecular Biosciences programme at the Gut Microbiota and Clostridia Research Group at Universidad Andrés Bello.

\section{DECLARATION OF INTEREST}

None.

\section{REFERENCES}

1. Rupnik M, Wilcox MH, Gerding DN. Clostridium difficile infection: new developments in epidemiology and pathogenesis. Nature Reviews Microbiology 2009; 7: 526-536.

2. Kuijper EJ, Coignard B, Tull P. Emergence of Clostridium difficile-associated disease in North America and Europe. Clinical Microbiology and Infection 2006; 12 (Suppl. 6): 2-18.

3. Alvarez M, et al. Diagnosis of Clostridium difficile diarrhoea: in search of a more efficient clinical focus [in Spanish]. Revista Medica de Chile 2001; 129: 620-625.

4. Herrera P, et al. High incidence and complications of Clostridium difficile diarrhoea among patients with renal diseases [in Spanish]. Revista Medica de Chile 2003; 131: 397-403.

5. Hernandez-Rocha C, et al. Epidemic Clostridium difficile ribotype 027 in Chile. Emerging Infectious Diseases 2012; 18: 1370-1372.

6. Sociedad Chilena de I. Report: Clostridium difficile outbreak at the Dr. Alejandro del Rio emergency hospital in Santiago, Chile [in Spanish]. Revista Chilena de Infectologia 2012; 29: 531-538.

7. Hernandez-Rocha C, et al. Prospective comparison of a commercial multiplex real-time polymerase chain 
reaction and an enzyme immunoassay with toxigenic culture in the diagnosis of Clostridium difficileassociated infections. Diagnostic Microbiology and Infectious Disease 2013; 75: 361-365.

8. Evans CT, Safdar N. Current trends in the epidemiology and outcomes of Clostridium difficile infection. Clinical Infectious Diseases 2015; 60 (Suppl. 2): S66-71.

9. Bauer MP, et al. Clostridium difficile infection in Europe: a hospital-based survey. Lancet 2011; 377: 63-73.

10. Bidet $\mathbf{P}$, et al. Development of a new PCR-ribotyping method for Clostridium difficile based on ribosomal RNA gene sequencing. FEMS Microbiol Letters 1999; 175: 261-266.

11. Rupnik M. Clostridium difficile toxinotyping. Methods in Molecular Biology 2010; 646: 67-76.

12. Oka K, et al. Molecular and microbiological characterization of Clostridium difficile isolates from single, relapse, and reinfection cases. Journal of Clinical Microbiology 2012; 50: 915-921.

13. Cohen SH, et al. Clinical practice guidelines for Clostridium difficile infection in adults: 2010 update by the society for healthcare epidemiology of America (SHEA) and the infectious diseases society of America (IDSA). Infection Control and Hospital Epidemiology 2010; 31: 431-455.
14. Quesada-Gomez C, et al. Emergence of an outbreakassociated Clostridium difficile variant with increased virulence. Journal of Clinical Microbiology 2015; 53: 1216-1226.

15. Argamany JR, et al. Regional and seasonal variation in Clostridium difficile infections among hospitalized patients in the United States, 2001-2010. American Journal of Infection Control 2015; 43: 435-440.

16. Freeman $\mathbf{J}$, et al. Pan-European longitudinal surveillance of antibiotic resistance among prevalent Clostridium difficile ribotypes. Clinical Microbiology and Infection 2015; 21: 248.e9-248.e16.

17. Noren T, Johansson K, Unemo M. Clostridium difficile PCR ribotype 046 is common among neonatal pigs and humans in Sweden. Clinical Microbiology and Infection 2014; 20: O2-6.

18. Pituch H, et al. Prevalence and association of PCR ribotypes of Clostridium difficile isolated from symptomatic patients from Warsaw with macrolide-lincosamidestreptogramin B (MLSB) type resistance. Journal of Medical Microbiology 2006; 55: 207-213.

19. Aguayo C, et al. Rapid spread of Clostridium difficile NAP1/027/ST1 in Chile confirms the emergence of the epidemic strain in Latin America. Epidemiology and Infection 2015; 143: 3069-3073. 